\title{
SOLUTION OF THE SIDE SLOPE PROBLEM CAUSED BY SLIDES ON THE PRISHTINA- PRIZREN HIGHWAY
}

\author{
Hysen AHMETI \\ Faculty for Civil Engineering and Infrastructure, University for Business and Technology, \\ Prishtina, Kosovo \\ Ragip BEHRAMI \\ Student, Ss. Cyril and Methodius University, Institute of Earthquake Engineering and \\ Engineering Seismology, Skopje, Republic of North Macedonia
}

\begin{abstract}
Landslides from the side slopes of the road are phenomena that are caused by changes in atmospheric conditions which have also affected the change of physical mechanical parameters of clay layers that have caused the stimulation and possible activation of landslides, but during the study of this area additional measures have been taken to solve this problem in order to prevent the possibility of landslides that are a traffic jams and a high risk on the highway at which the maximum speed allowed, according to the standards based on which the road is constructed, it is foreseen to be $120 \mathrm{~km} / \mathrm{h}$, then to reduce the risk of not coming to the traffic jams on the highway that can cause fatal accidents on that segment of the road according to the case shown in Fig. 1 as well as to find a solution to avoid this phenomenon of slips is made the comparison of the existing condition of the side slopes of the road and the designed one, which is the purpose of this paper, calculating the stability of the side slopes according to the existing condition and that designed taking into account the physical - mechanical parameters with the safety factor allowed according to geotechnical standards.
\end{abstract}

Keywords: landslide problem, technical solution, side slopes

Cite this Article: Hysen AHMETI and Ragip BEHRAMI, Solution Of The Side Slope Problem Caused By Slides On The Prishtina-Prizren Highway, International Journal of Civil Engineering and Technology, 11(11), 2020, pp. 65-74.

https://iaeme.com/Home/issue/IJCIET?Volume=11\&Issue=11

\section{INTRODUCTION}

In recent years in Kosovo have been activated a large number of landslides, especially in road infrastructure on the highway Prishtina - Prizren as part of the movement of clay layers of 
side slopes with poor physical-mechanical parameters, that the possibility of landslides are possible even with the change of atmospheric conditions where the presence of surface and groundwater is present especially during rain and snow that over time change the existing parameters that affect the breakdown of the structure and texture of the geomechanical parameters of the soil of the side slopes.

In this segment of the highway there have been slides on the side slopes which are evident as can be seen in Fig. 1, however, taking into account the actual situation on the ground, calculations have been made to verify the stability of the slope with the existing situation according to the geological profile presented in Fig. 5, and has been found to have a safety factor less than $\mathbf{F S}<\mathbf{1}$.

The construction of the highway is a major engineering work that represents a large frequency of vehicle traffic, therefore the purpose and importance of this paper is the design and rehabilitation of side slopes according to the geometry designed according to Fig. 6 applying the calculation methods according to the Eurocode EC-7 and EC-8 [7], [8] with the allowed safety factor Fs $>\mathbf{1 . 2}$ with the designed state shown in Fig. 8b and Fig. 9b which is also the purpose of this paper.

In the side slopes where the landslides occurred mainly heterogeneous clays dominate where a part of the excavated material is placed on the side slopes to create the geometry of the scale in full compliance with geomechanical parameters [2] and at the same time application of calculation methods by designing height and side slope geometry angle with safety factor FS > $\mathbf{2}$ applying geotechnical standards.

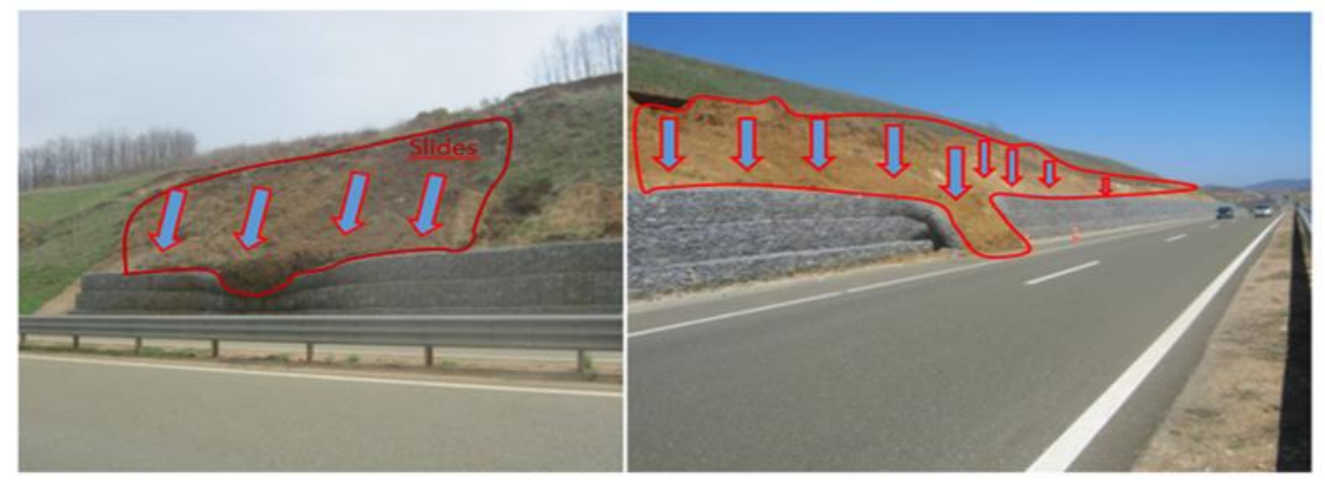

Figure 1: The actual condition of the slides on the highway

\section{DESCRIPTION OF THE STUDIED AND ANALYZED ZONE}

The position in which the slide occurred on the highway Prishtina - Prizren is presented according to the road map of Kosovo Fig. 2, in the side parts of the highway where side slides have occurred, which have a length of about $5 \mathrm{~km}$ distributed in different parts where the presence of heterogeneous brown in bloom clay with a small presence of humus dominates which are expressed in the two side parts of the road where they are also observed based on the actual situation at the site according to Fig. 1.

In this studied area it is practiced to take the following factors: regulation of the geometry of the side slopes by applying analytical and graphical calculations, opening channels, placing geotextiles, construction of retaining walls according to the safety factor allowed according to the geotechnical standards where we have to do with engineering works of this kind. 


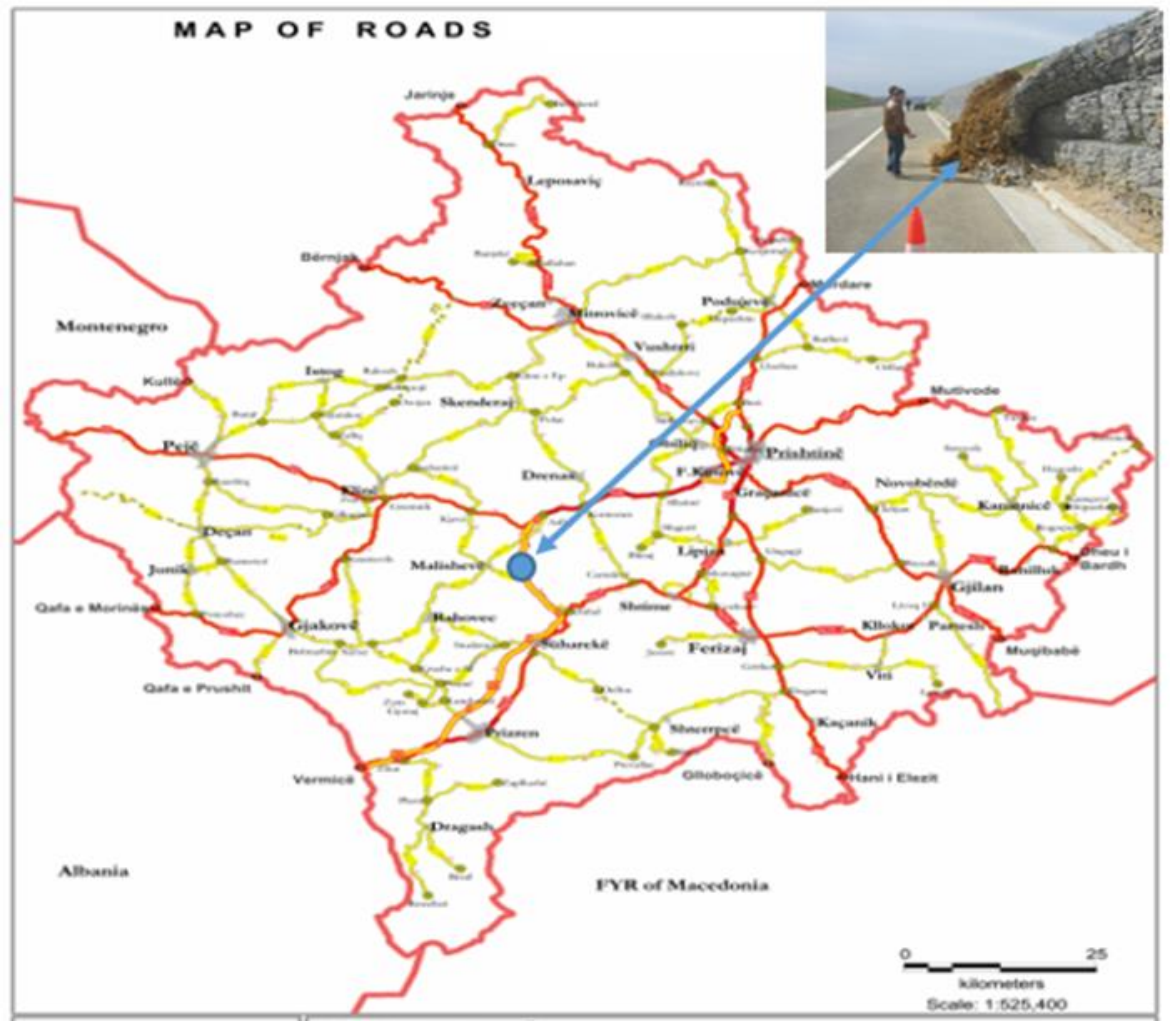

Figure 2: Road map of Kosovo with sliding positions.

\section{PROBLEM STATEMENT}

Slope stability is a critical problem displayed on the side roads of the highway where during the autumn and winter season the presence of surface and groundwater is higher, where the consistency of the soil is unstable, the soil undergoes changes from the state of half strong pass in the running state.

The main driving problem that caused the sliding of the clay masses in this case is the non-functioning - closure of canals for drainage of surface water and groundwater, lack of geotextile on the side slopes in certain parts that the consistency index $\mathrm{CI}<0$, with the consistency of unstable soils, with poor cohesion bonds, etc.

Then, based on the existing situation, it is foreseen to take additional measures to solve these landslide phenomena by designing and calculating a geometry of stable slopes with physical-mechanical parameters according to Eurocodes EC-7 and EC-8 with the long-term safety factor by implemented the two possible final solution options according to (Fig. 8a) and (Fig. 9b).

\section{METHODOLOGY AND MATERIALS}

Based on the actual situation on the site according to Fig. 1 the realization of the field work was carried out in the following phases: the collection of concrete data at the site from the landslide area as the collection of geological - engineering information, within these activities the physical parameters are extracted: GS - specific weight, $\gamma$ - volumetric weight, $\gamma \mathrm{d}$ volumetric weight in the dry state, $\mathrm{n}$ - porosity, $\mathrm{e}$ - porosity coefficient, $\mathrm{w}$ - moisture, all these parameters are presented in table no. 1 using equations $(1,2,3,4)$ as well as mechanical parameters: friction angle $\varphi$ and cohesion $C$ obtained in the laboratory with the apparatus with three-axis test and the direct one according to Fig. 3 and Fig. 4 at the INKOS Institute [2]. 
According to the data mentioned above, the statistical processing is considered as well as the reduction of angle $\varphi^{\circ}$ and cohesion $\mathbf{C}$ according to equations $(11,12)$ with the final values for the calculation of lateral slopes with the allowed safety factor based on geological layers according to Eurocode (EC-7), according to [3,4,5,6,7,9].

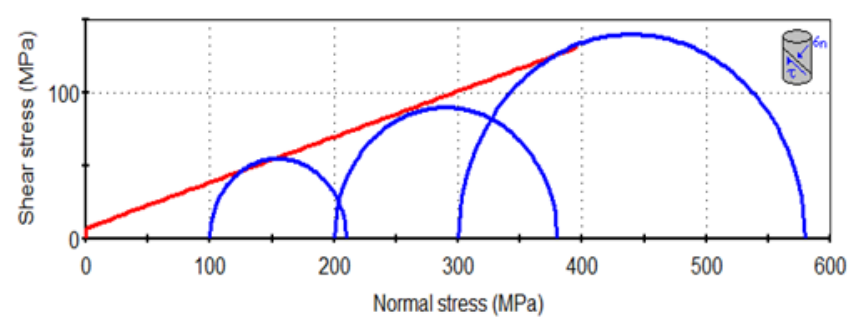

Figure 3: Tri-axial test

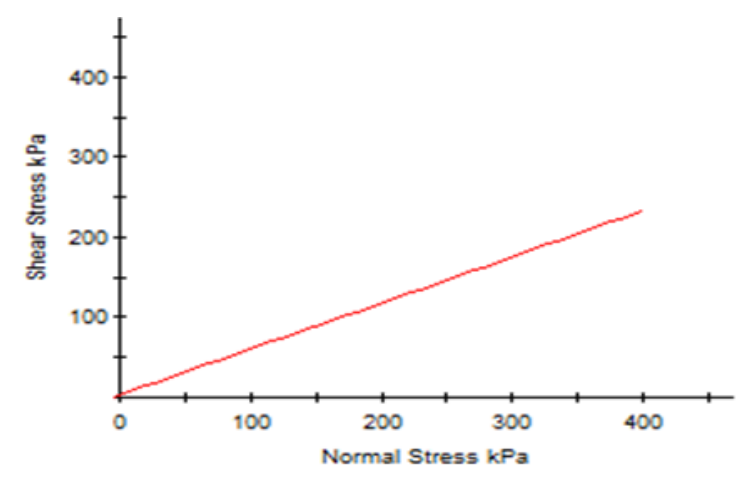

Figure 4: Direct Test

\section{STATISTICAL PROCESSING OF CLASSIFICATION PARAMETERS}

The arithmetic mean value according to [10] was used to determine the classification parameters.

$$
\overline{\mathrm{X}}=\frac{1}{\mathrm{n}} \sum_{\mathrm{i}=1}^{\mathrm{N}} \mathrm{x}_{\mathrm{i}}
$$

where are: $\mathrm{n}$ - number of samples, $\mathrm{X}_{\mathrm{i}}$ - characteristic values of one test

Standard error

$$
S^{2}=\frac{1}{(n-1)} \sum_{i=1}^{N}\left(x_{i}-\bar{x}\right)^{2}
$$

Coefficient of variation

$$
\begin{array}{ll} 
& \mathrm{S}= \\
\frac{\mathrm{X}}{\overline{\mathrm{V}}} &
\end{array}
$$

The obtained results of physical parameters for each lithological layer of the side slopes are presented in table 1 and table 2. 
Solution Of The Side Slope Problem Caused By Slides On The Prishtina-Prizren Highway

Table 1: Statistical indicators for brown clay [10]

\begin{tabular}{|l|c|c|c|c|c|c|}
\hline $\begin{array}{c}\text { Statistical } \\
\text { indicator }\end{array}$ & $\begin{array}{c}\mathbf{G} \mathbf{s} \\
{\left[\mathbf{k N} / \mathbf{m}^{\mathbf{3}}\right]}\end{array}$ & $\boldsymbol{\gamma}\left[\mathbf{k N / \mathbf { m } ^ { 3 } ]}\right.$ & $\begin{array}{c}\boldsymbol{\gamma}_{\mathbf{d}} \\
{\left[\mathbf{k N} / \mathbf{m}^{\mathbf{3}}\right]}\end{array}$ & $\mathbf{w}[\%]$ & $\mathbf{n ~ [ \% ]}$ & $\mathbf{e}$ \\
\hline $\mathrm{X}_{\min }=$ & 24.50 & 17.00 & 11.50 & 23.00 & 40.00 & 0.38 \\
\hline $\mathrm{X}_{\operatorname{mes}}=$ & 26.48 & 18.97 & 13.253 & 41.933 & 37.06 & 0.684 \\
\hline $\mathrm{X}_{\max }=$ & 28.70 & 21.00 & 15.00 & 65.00 & 53.00 & 0.98 \\
\hline$\Sigma \mathrm{X}_{\mathrm{i}}=$ & 284.55 & 284.55 & 198.80 & 629.00 & 556.00 & 10.26 \\
\hline $\mathrm{n}=$ & 15.00 & 15.00 & 15.00 & 15.00 & 15.00 & 15.00 \\
\hline $\mathrm{S}=$ & 1.048094 & 0.954 & 1.023 & 13.1446 & 14.355 & 0.179 \\
\hline $\mathrm{V}=$ & 0.05525 & 3.60 & 0.0772 & 0.31346 & 0.3872 & 0.2629 \\
\hline
\end{tabular}

Table 2: Brown clay with the presence of humus

\begin{tabular}{|c|c|c|c|c|c|c|}
\hline $\begin{array}{l}\text { Statistical } \\
\text { indicator }\end{array}$ & $\begin{array}{c}\text { Gs } \\
{\left[\mathrm{kN} / \mathbf{m}^{3}\right]}\end{array}$ & $\gamma\left[\mathrm{kN} / \mathrm{m}^{3}\right]$ & $\begin{array}{c}\gamma_{\mathbf{d}} \\
{\left[\mathrm{kN} / \mathbf{m}^{3}\right]}\end{array}$ & $\mathrm{w}[\%]$ & n [\%] & $\mathbf{e}$ \\
\hline$X_{\min }=$ & 23.50 & 18.00 & 10.50 & 24.00 & 35.00 & 0.37 \\
\hline$X_{\text {mes }}=$ & 25.48 & 17.86 & 12.253 & 40.833 & 36.06 & 0.654 \\
\hline$X_{\max }=$ & 26.70 & 20.00 & 14.00 & 54.00 & 50.00 & 0.88 \\
\hline$\Sigma X_{i}=$ & 274.55 & 274.55 & 188.80 & 620.00 & 546.00 & 9.26 \\
\hline $\mathrm{n}=$ & 15.00 & 15.00 & 15.00 & 15.00 & 15.00 & 15.00 \\
\hline $\mathrm{S}=$ & 1.018094 & 0.854 & 1.033 & 12.1446 & 13.2435 & 0.169 \\
\hline $\mathrm{V}=$ & 0.04525 & 3.30 & 0.0872 & 0.21324 & 0.3652 & 0.2528 \\
\hline
\end{tabular}

\subsection{STATISTICAL PROCESSING OF HARDNESS PARAMETERS WITH THREE-AXIS TEST}

Statistical processing of hardness parameters obtained with the three-axis test was done according to equation (4), (5), (6), (7), (8) with reliability $\mathrm{k}=95 \%$.

$$
\begin{aligned}
& \operatorname{tg}_{\varphi}=\frac{\alpha-1}{2 \sqrt{\alpha}},\left[^{\circ}\right] \\
& C=\frac{b}{2 \sqrt{\alpha}},\left[\frac{k N}{m^{2}}\right] \\
& a=\frac{1}{\Delta}\left(n \sum \sigma_{1} \sigma_{3}-\sum \sigma_{1} \sum \sigma_{3}\right) \\
& b=\frac{1}{\Delta}\left(\sum \sigma_{3}^{2} \sum \sigma_{1}-\sum \sigma_{3} \sum \sigma_{1} \sigma_{3}\right) \\
& \Delta=n\left(\sigma_{3}\right)^{2}-\left(\sigma_{3}\right)^{2}
\end{aligned}
$$

where are:

$\sigma 1, \sigma 3$ - main maximum stresses $[\mathrm{kN} / \mathrm{m} 2]$

The results obtained from statistical processing are presented in table 3 and table 4 . 
Table 3: Statistical indicators obtained with the tri-axial test according to geological strata

\begin{tabular}{|c|c|c|}
\hline $\begin{array}{c}\text { Parameters of } \\
\text { strength }\end{array}$ & Brown clay & $\begin{array}{c}\text { Brown clay with the } \\
\text { presence of humus }\end{array}$ \\
\hline$\varphi\left[{ }^{\circ}\right]$ & 32.00 & 30.00 \\
\hline $\mathrm{C}\left[\mathrm{kN} / \mathrm{m}^{2}\right]$ & 10.00 & 8.50 \\
\hline$\gamma\left[\mathrm{kN} / \mathrm{m}^{3}\right]$ & 18.97 & 17.86 \\
\hline
\end{tabular}

\subsection{Determining the calculation parameters}

For the determination of mechanical parameters (hardness) are mainly used two devices which have given different results, then applying equation (9) and equation (10) for calculation it is necessary to unify the mechanical parameters of hardness that are presented in table 4 .

$$
\begin{aligned}
& \varphi_{\text {përgj. }}=\frac{\varphi_{\mathrm{pd}}^{\mathrm{N}} \cdot n_{p d}+\varphi_{\text {trea }}^{\mathrm{N}} \cdot n_{\text {trea }}}{n_{p d}+n_{\text {trea }}},\left[^{\circ}\right] \\
& \mathrm{C}_{\text {përgj. }}=\frac{\mathrm{C}_{\mathrm{pd}}^{\mathrm{N}} \cdot n_{p d}+\mathrm{C}_{\text {trea }}^{\mathrm{N}} \cdot n_{\text {trea }}}{n_{p d}+n_{\text {trea }}},\left[\frac{\mathrm{KN}}{\mathrm{m}^{2}}\right]
\end{aligned}
$$

npd - number of samples with shearing test

ntrea - number of samples with tri-axial test

The reduction of hardness parameters is done according to (Terzaghi - Kumbhojkar)

$\varphi^{\prime}=\operatorname{tag}^{-1}\left(\frac{2}{3} \operatorname{tag} \varphi\right)$

$$
c^{\prime}=\frac{2}{3} c
$$

$\sum M_{0}=\sum_{n=1}^{7} W r \sin \alpha-\sum_{n=1}^{7} \operatorname{Tr}=0$

$\sum M_{0}=\sum_{n=1}^{7} W \sin \alpha-\sum_{n=1}^{7} T=0$

$\mathrm{T}=\frac{\mathrm{C}^{\prime} \cdot \mathrm{l}+\tan \emptyset^{\prime}(\mathrm{N}-\mathrm{ul})}{\mathrm{F}}$

Substituting equations (12) and (13) we have:

$$
\mathrm{F}=\frac{\sum_{n=1}^{7} C^{\prime} l+\tan \emptyset^{\prime}(N-u l)}{\sum_{n=1}^{7} w \sin \alpha}
$$

$\mathrm{N} \cos \alpha+\mathrm{T} \sin \alpha-\mathrm{W}=0$

$$
\begin{aligned}
& \mathrm{N} \cos \alpha+\frac{\mathrm{C}^{\prime} 1+\tan \emptyset^{\prime}(\mathrm{N}-\mathrm{ul})}{\mathrm{F}} \sin \alpha-\mathrm{W}=0 \\
& \mathbf{N}=\left(\mathrm{W}-\frac{\mathrm{C}^{\prime} \mathrm{l}-\tan \emptyset^{\prime} \mathrm{ul}}{\mathrm{F}} \sin \alpha\right) /\left[\cos \alpha\left(1+\frac{\tan \phi^{\prime} \tan \alpha}{\mathrm{F}}\right)\right] \\
& \mathrm{F}=\frac{1}{\sum_{\mathrm{n}=1}^{7} \mathrm{~W} \sin \alpha} \sum_{\mathrm{n}=1}^{7}\left[\mathrm{C}^{\prime} \mathrm{l}+\tan \emptyset^{\prime}\left(\frac{\left(\mathrm{w} \frac{\mathrm{C}^{\prime} 1-\tan \phi^{\prime} \mathrm{ul}}{\mathrm{F}}\right)}{\cos \alpha\left(1+\frac{\tan \phi^{\prime} \mathrm{ul}}{\mathrm{F}}\right)}\right)\right] \\
& \text { https://iaeme.com/Home/journal/IJCIET }
\end{aligned}
$$


Solution Of The Side Slope Problem Caused By Slides On The Prishtina-Prizren Highway

Table 4: Final geomechanical parameters for calculation

\begin{tabular}{|c|c|c|c|}
\hline \multirow{2}{*}{ Lithological layers } & \multicolumn{3}{|c|}{ Physical-mechanical parameters } \\
\cline { 2 - 4 } & $\boldsymbol{\varphi}\left[^{\mathbf{0}}\right]$ & $\mathbf{C}\left[\mathbf{k N} / \mathbf{m}^{\mathbf{2}}\right]$ & $\gamma\left[\mathbf{k N} / \mathbf{m}^{\mathbf{3}}\right]$ \\
\hline Brown clay & 22.60 & 6.60 & 18.97 \\
\hline $\begin{array}{c}\text { Brown clay with the } \\
\text { presence of humus }\end{array}$ & 21.50 & 5.60 & 17.86 \\
\hline
\end{tabular}

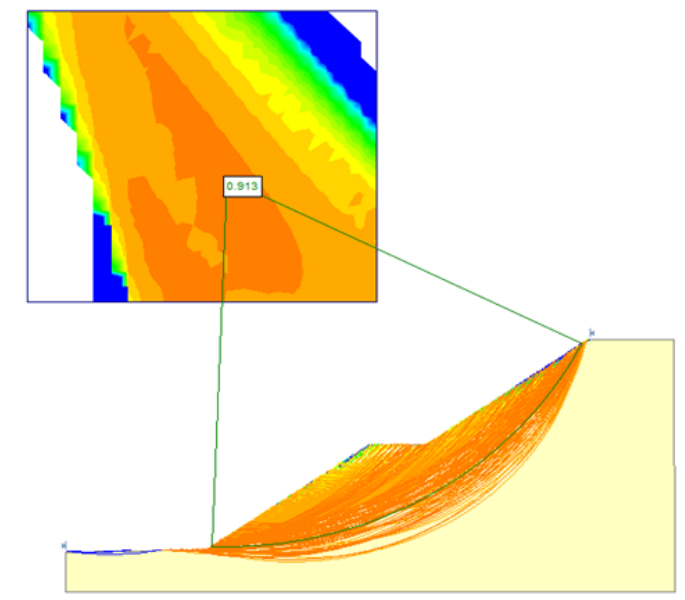

Figure 5: Calculation of the slope according to the existing situation with the safety factor FS $<1$

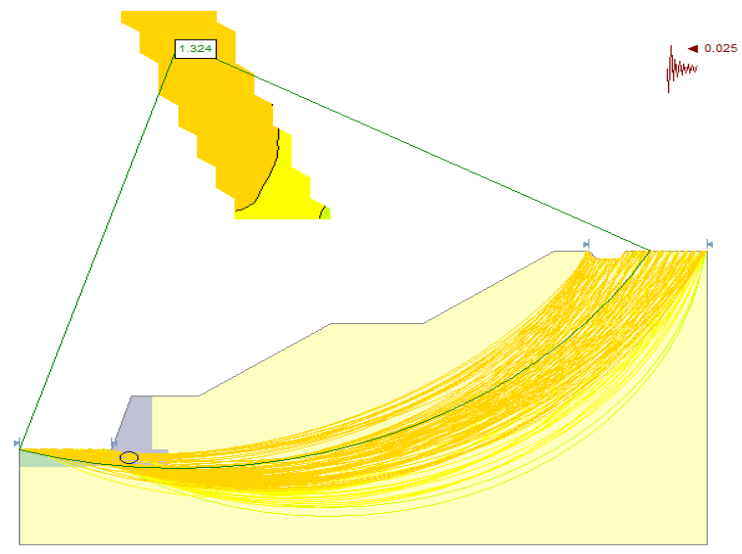

Figure 6: Calculation of the slope according to the designed condition with the safety factor FS $>1.20$

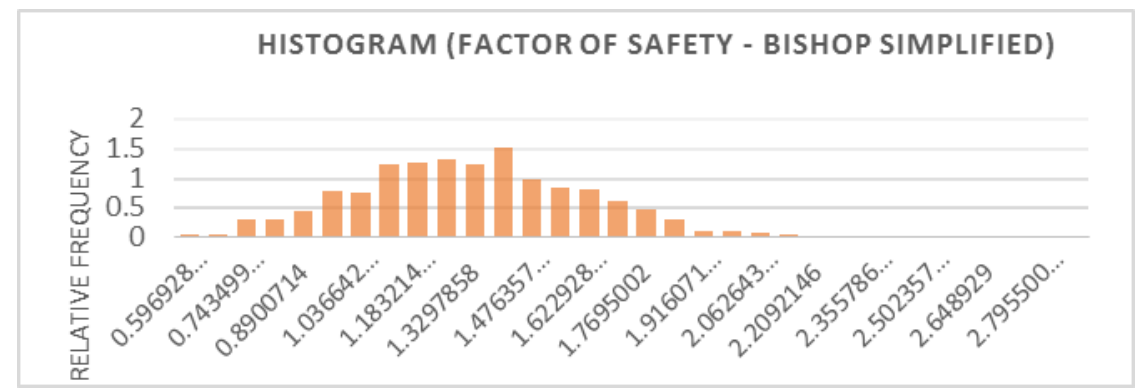

Figure 7: Presentation of the histogram with the safety factor 


\section{CALCULATION METHODS}

By applying the physical-mechanical parameters for calculation, software programs have been used according to [7], [8] by applying equation (18) with the designed state with the general and partial angle according to Fig. 8a and Fig. 9a.

The solution proposal is analyzed and designed as two possible cases which can be executed in practice to prevent landslides of lateral slopes.

The first case is the calculation of the slope geometry with the retaining wall according to the designed condition according to Fig. 8a with the general slope angle $\boldsymbol{\alpha}=\mathbf{2 0}{ }^{\circ}$ and the partial slope angle $\boldsymbol{\beta}=\mathbf{2 9}^{\circ}$ with a safety factor greater than $\mathbf{F S}>\mathbf{1 . 2 0}$, the results are presented in table 5, while as a final condition it is designed and analyzed as in (Fig. 8b).

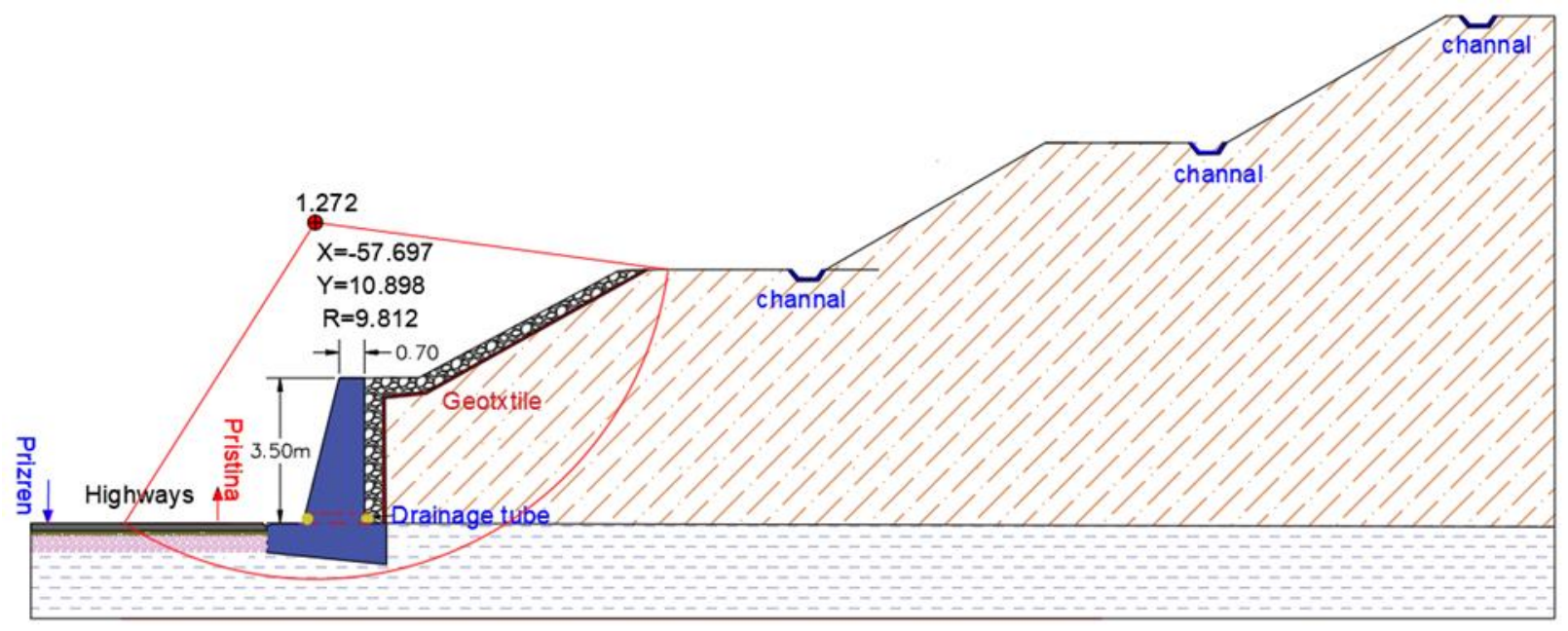

Figure 8.a) Calculation of the side slope with the reinforced concrete retaining wall

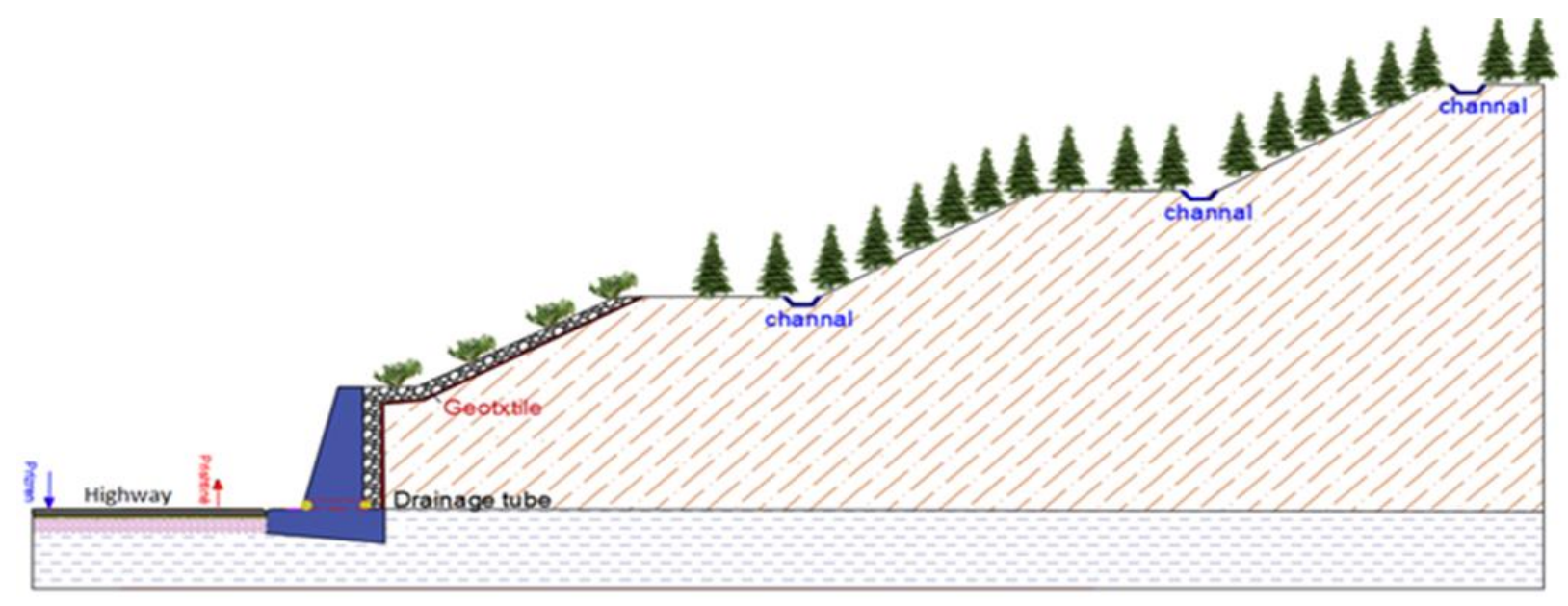

Figure 8.b) The final state of the slope solution

The second case is proposed gabion protective wall according to Fig. 9a with general angle $\alpha=\mathbf{1 8}^{\circ}$ and partial angle $\boldsymbol{\beta}=\mathbf{2 5}{ }^{\circ}$ with safety factor $\mathbf{F S}>\mathbf{1 . 2 0}$ according to equation (18) the results are presented in more detail in table 6 , while as a final condition it is presented in (Fig. 9b). 


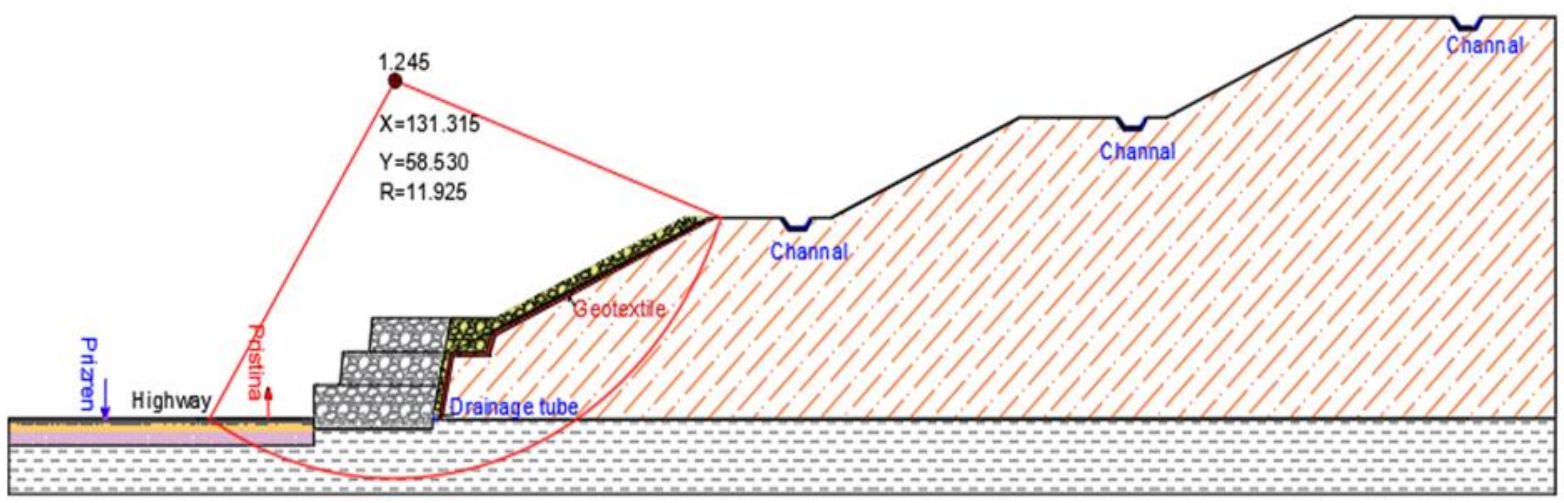

Figure 9.a) Calculation of lateral slopes with gabion walls

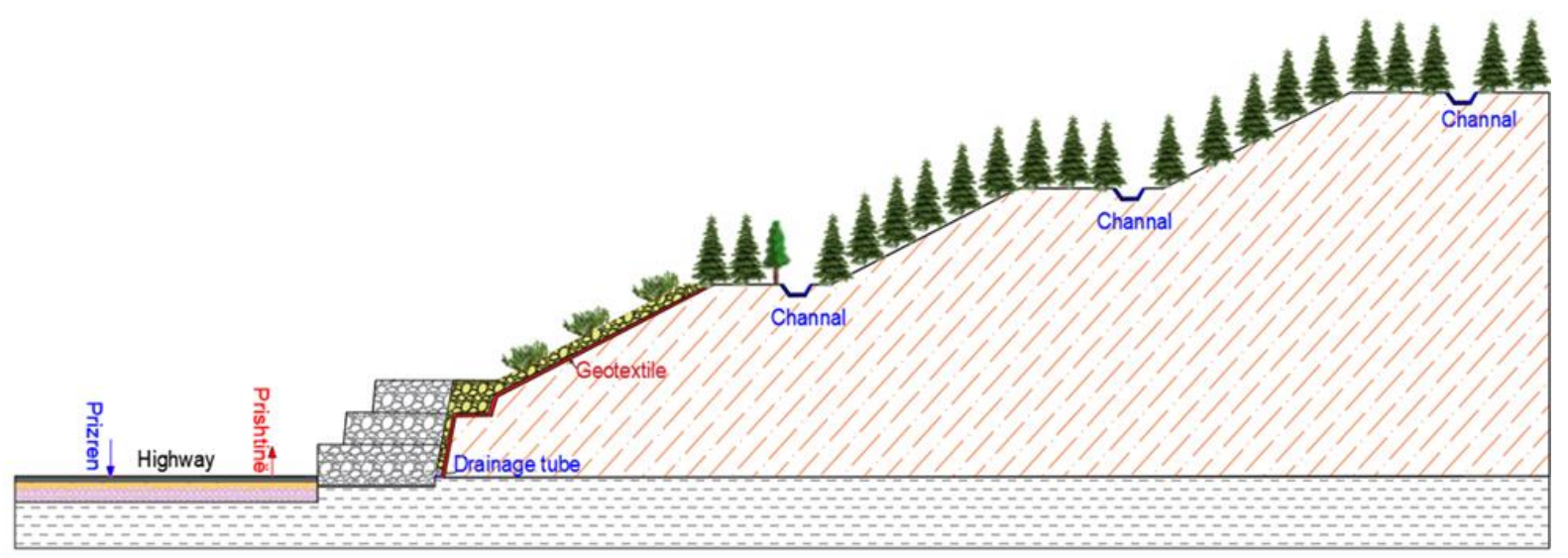

Figure 9.b) The final condition of the side slopes presented also from the aspect of the environment

\section{RESULTS}

For the solution of the problem of side slopes and the elimination of landslide phenomena in the road segment on the highway Prishtina - Prizren, a large number of methods have been applied which are presented in table 5 and table 6 with the condition designed according to Fig. 8a and Figure 9b with safety factor FS $>2$ applying geomechanical parameters according to table 4 and final state according to Fig. 10.

Table 5: Calculation of slopes according to designed geometry [7]

\begin{tabular}{|c|c|}
\hline Method & Factor of Safety \\
\hline Bishop & 1.272 \\
\hline Spencer & 1.284 \\
\hline GLE & 1.280 \\
\hline Janbu Corrected & 1241 \\
\hline Ordinary / Fellenius & 1.256 \\
\hline Corps of Engineers $* 1$ & 1.294 \\
\hline
\end{tabular}




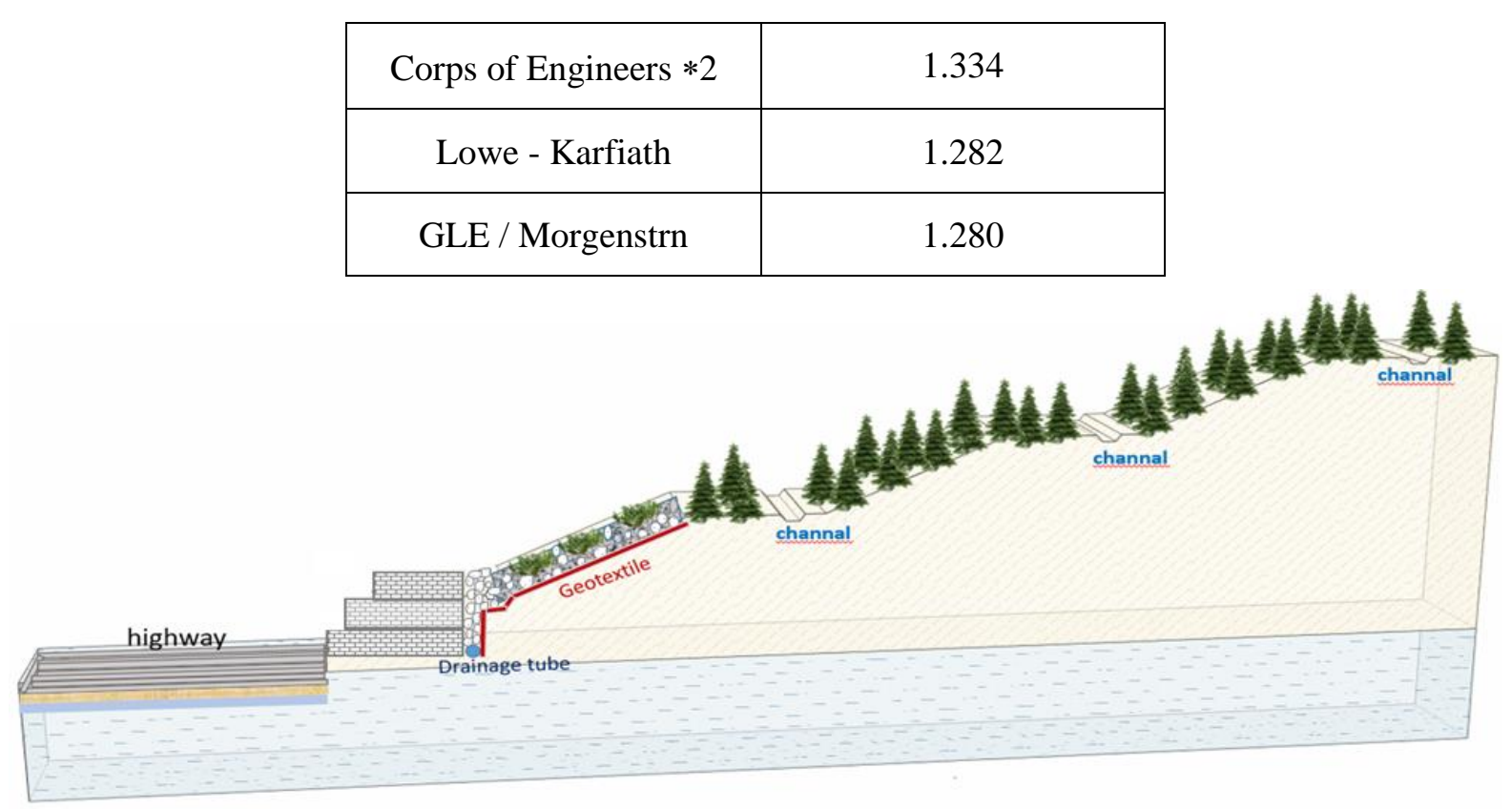

Figure 10: 3D view of the final slopes with designed condition

\section{CONCLUSIONS}

Based on the analysis of geomechanical parameters for deriving real values, the statistical processing mentioned above was applied for the calculation of side slopes with the designed condition according to (Fig. 8a and 8b) and (Fig. 9a and 9b) applying also the environmental part according to 3D profile (Fig. 10) with the safety factor according to table 5 and table 6 using almost all existing calculation methods according to [7] and [8] and at the same time the application of Eurocode EC 7-1 and EC 7-2 for geotechnical designs according to EN (2010).

According to the designed condition on the side slopes, both analyzed cases are possible to be realized on the site taking into account the dimensioning of the walls according to the designed condition, placement of drainage pipes, placement of geotextile, respecting the partial angle and the general angle, opening of canals for drainage of surface waters and groundwater. All these measures will increase the safety factor of the side slopes of the road and will reduce the risk of accidents.

\section{REFERENCES}

[1] Abramson, L.W., Lee, T.S., Sharma, S. and Boyce, G.M. (2001), Slope Stability and Stabilization Methods, 2nd edition, John Wiley \& Sons

[2] Laboratori Gjeomekanik, (2017), Instituti INKOS, ISO 9001, Kastriot-Prishtinë

[3] Braja M. Das, Nagaratnam Sivakugan (2017), Principles of Geotechnical Engineering, USA.

[4] Ming Xiao (2015), Geotechnical Engineering Design, The Pennsylvania State University, University Park, USA

[5] Bud Bond, A. J. and Harris, A. J., 2008, Decoding Eurocode 7, Taylor \& Francis.

[6] British Standards Institution, 2004, Eurocode 7: Geotechnical design - Part 1: General rules, BS EN 1997-1, London, UK.

[7] Software Slide V6 https://www.rocscience.com/software/geotechnical-tools

[8] Geotechnical software Fine GEO5 2019

[9] Smith, 2006, Smith's Elements of Soil Mechanics, 8th Edition, Blackwell Publishing.hu. M. (2014), Soil mechanics and foundations

[10] Golden Software Surfer 16, www.golden software.com 